\title{
Case Study On Illness Perception And Treatment Belief In Breast Cancer Patients Who Undergo A Traditional Treatment
}

\author{
Arina Shabrina ${ }^{1}$, Aulia Iskandarsyah ${ }^{2}$ \\ ${ }^{1}$ Faculty of Psychology, Universitas Padjajaran, Bandung, Indonesia \\ ${ }^{2}$ Department of Clinical Psychology, Universitas Padjajaran, Bandung, Indonesia \\ *Email: arina12003@mail.unpad.ac.id
}

\begin{abstract}
This case study aimed to describe the illness perception, medical and traditional treatment belief in breast cancer patients. Traditional treatment referred to health practices beyond medical treatment. Five breast cancer patients were recruited from an online survey, cancer community and traditional treatment clinic. They completed a demographic and clinical characteristic form, IPQ-R, BMQ, CAMBI and interviewed. Descriptive statistic and qualitative analysis were used to analyze the data. The majority of participants had a positive illness perception. They believed in their ability to control the illness, appraised their illness as an acute condition and believed the treatment helped them control the illness. The most selected cause of breast cancer was a psychological factor; stress and the cause which considered important associated with participant's behavior.They also had a lower belief in medical treatment, worried about the negative side effects and tend to feel there is no need to undergo medical treatment.They had a higher belief in traditional treatment, involving belief in natural treatment, participation in treatment and holistic health. Most breast cancer patients who undergo traditional treatment had a positive illness perception, lower belief in medical treatment and higher belief in traditional treatment.
\end{abstract}

Key Words: illness perception, treatment belief, breast cancer

\section{Introduction}

Breast cancer is one of leading cause of death among women in the world. Breast cancer was a type of cancer with the highest prevalence among Indonesian women in 2013, with a prevalence $0,5 \%$ (Indonesian Ministry of Health, 2013). In Indonesia, the mortality and incidence rate of breast cancer is still high because the patient was found at the advanced stage of cancer. Excessive fear is the reason why women came late to check their breast cancer symptoms. Around $60-70 \%$ breast cancer patients sought medical treatment when it was too late (Poorwo \& Suhardi, 1992 \& Wasisto, 1991 in Tjindarbumi \& Mangunkusumo, 2002).

Most of the Indonesian women described breast cancer as a dangerous illness, fatal and incurable (Iskandarsyah et al., 2013). They had a negative belief about breast cancer and its treatment that could cause disability, worsen their appearance and have an economic impact (Nurleli, Petpichetchian \& Maneewat, 2014). Despite these negative beliefs, the patient's perception towards their illnesses is an important factor affecting patient's treatment decision between traditional and medical treatment.

Breast cancer patients perceived that certain medical procedure would be painful (Muhamad, Merriam \& Suhami, 2012). Thus, promoting the growing interests on traditional treatment among breast cancer patient. Also, this perception is supported by patient's concern regarding the side effect of the medical cancer treatment, media influence and hope to get a holistic care. In developing 
country, the use of traditional treatment was often associated with the ease of access and affordability (WHO, 2002).

Data from Basic Health Research in 2013 showed that $30,4 \%$ of the people in Indonesia have used traditional treatment. The main reasons for using traditional treatment were to maintain health, motivated to try the treatment and various reasons associated with traditions and beliefs. The previous survey about traditional treatment use in a various group of patients based on the type of cancer showed that breast cancer patients were the biggest group of patients who used one form of traditional treatment; the herbal treatment (Damery et al., 2011).

Breast cancer patients in Malaysia tend to visit traditional treatment clinic before they went to hospital as suggested by their community (Muhamad et al., 2012), including in Indonesia. Breast cancer patients in Indonesia prefer consult with traditional treatment therapist because they not only focused on patient's physical symptoms but also on their feeling (Iskandarsyah et al., 2013). As a qualitative study in Malaysia showed that breast cancer patients believed in traditional treatment could cure breast cancer without breast removal surgery and not experiencing the side effects from cancer treatment (Yusuf, Hadi, Mahamood, Ahmad \& Keng, 2013).

Regarding the treatment decisions, the patient's decision-making process to undergo a treatment is different in each society. In nonWestern society, the decision-making process to undergo medical treatment is slower and involving many people (Foster \& Anderson, 2006). The unsupportive sociocultural factor in the society, such as belief in traditional treatment or traditional healer became a problem too. Inadequate health facilities, bad infrastructures and information system worsen the development of cancer incidence control program (Pal, 2002).
In Indonesia, breast cancer patients tend to look for treatment to the traditional healer or other traditional treatment therapist before they visited a health care provider (Joordan, 1985; Sarwono, 1992; \& Slamet-Velsink, 1992 in Sarwono, 2012). As the long-term effect of undergoing the traditional treatment could cause breast cancer patients to visit a doctor later when their condition already in advance stage. The severe condition causing them to have lower life expectancy, expensive medical cost and realization of how difficult it is to cure their terminal condition.

As a patients, the individual actively solve the problems and have their idea about the illness and its treatment (Horne, 1997). Perception about the illness and treatment belief are two factors which influenced how the patients cope with their illness. The decision-making about treatment can be explained through patient's illness perception and their belief about the treatment available for them, whether it is a medical or traditional treatment.

Illness perception and treatment belief can be different for everyone, based on information available for them. Each patient would show a certain perception of every illness based on the symptoms and its chronicity (Leventhal et al., 1980). There are breast cancer patients who prefer to undergo a traditional treatment rather than medical treatment to cope with their illness, even though there is little evidence that supports this alternative. Illness perception and treatment belief can contribute to breast cancer patient's treatment decision too. Therefore, this research aimed to describe the illness perception and treatment belief in breast cancer patients who undergo a traditional treatment.

\section{Methods}

Sample. The sample of this study consisted of 5 breast cancer patients recruited through purposive sampling. They were recruited from an online survey, recommendation from cancer community groups and visitation to traditional 
treatment clinic in Bandung. Participant eligibility was based on the diagnosis of breast cancer from the doctor, age ( $>18$ years old), visitation to traditional treatment, undergo a traditional treatment at least twice and willing to participate voluntarily in this study. Potential participants were approached through social media (WhatsApp) and text message, which then followed up after they determine interest and eligibility to participate in the study. An appointment for a meeting was set in their home to discuss the study and data collection procedure.

Research Design. The research design used in this study was a mixed method research with concurrent embedded strategy and used a descriptive method. This study combined and collected both quantitative and qualitative data.

\section{Instrument and Measurement.}

\section{Demographic and Clinical Characteristic}

A standard demographic and clinical characteristic form, were used to collect selfreport data on age, marital status, education level, employment status, family history of breast cancer, stage of cancer, type of treatment.

\section{The Revised Illness Perception Questionnaire (IPQ-R)}

Nine dimensions of illness perception were measured by the IPQ-R (Moss-Morris et al., 2002). The identity dimension consists of 14 common symptoms, associated with one's current health condition. This dimension was excluded in this study because the symptoms of breast cancer were different for each person. The IPQ-R items were reworded to be acceptable to the participants of this study, for example, the word 'illness' was replaced with 'breast cancer'.

Six items measured beliefs about the chronicity of the illness (timeline, e.g., "My breast cancer is likely to be permanent rather than temporary), six items measured beliefs in the consequences of the illness (consequences, e.g., 'My breast cancer is a serious condition'), six items measured belief in owning control over the illness (personal control, e.g., 'I have the power to influence my breast cancer), five items measured beliefs in the ability of treatment to control the illness (treatment control, e.g., 'My treatment will be effective in curing my breast cancer), five items measured beliefs in the coherence understanding of the ilness (illness coherence, e.g., 'I have a clear picture or understanding of my breast cancer), four items measured beliefs in cyclical nature of the illness (timeline cyclical, e.g., 'The symptoms of breast cancer change a great deal from day to day), and six items measured emotional representation of the illness (emotional representation, e.g., 'I get depressed when I think about my breast cancer). Causal beliefs about the illness were assessed by 18 items covering range of possible causes, including emotional factor (e.g. 'stress), lifestyle (e.g. 'smoking'), environmental (e.g. 'pollution') and chance (e.g. 'accident). Also, one additional open-ended question to assess patient's causal belief where the participant was asked to list the three most important causal factors in their illness.

Responses from the beliefs about chronicity of illness, consequences, personal and treatment control, the coherence of the illness, cyclical nature of the illness and emotional representation and causality of illness were scored on a 5-point Likert-type scale (where $1=$ strongly disagree, $2=$ disagree, $3=$ uncertain, $4=$ agree, and $5=$ strongly agree). In statistical analysis, response scale of items IP1, IP4, IP8, IP15, IP17, IP18, IP19, IP23, IP24, IP25, IP26, IP27 and IP36 was reserved for obtaining the same response direction with the other items.

The result from the IPQ-R try-out process in the first study showed that all dimensions in the questionnaire were internally consistent $(\alpha=0,7-0,9)$ (Moss-Morris et al., 2002). While the Cronbach's Alpha for each dimension in 
the Indonesian version of the IPQ- $\mathrm{R}$ is as follow : identity $=0,568$, timeline $=0,898$, consequences $=0,795$, cause of illness $=0,77$, personal control $=0,635$, timeline cyclical $=0,629$ and treatment control $=0,455$, illness coherence $=0,911$ and emotional representation $=0,852$.

\section{Belief About Medication Questionnaire (BMQ)}

Patient's beliefs about medical treatment were assessed using the BMQ through 18-items in the questionnaire (Horne at al., 1999). The BMQ comprised of four dimensions which are, five items assessing patient's beliefs about necessity of medical treatment for their illness (specific necessity, e.g.' My health, at present, depends on my medicines', five items assessing their concern about potential adverse side effect of using it (specific concern, e.g. 'I sometimes worry about long-term effects of my medicines ', four items assessing beliefs about potential harm of using medication in general (general harm, e.g. 'All medicines are poison 'and four items assessing beliefs about the overuse of prescription medicine by doctors (general overuse, e.g. 'Doctors place too much trust on medicines').

Responses scored on a 5-point Likert-type scale (where $1=$ strongly disagree, $2=$ disagree, $3=$ uncertain, $4=$ agree, and $5=$ strongly agree). The scores for each dimension obtained from the sum of all items within each dimension. The total score was obtained by summing the scores from each item in the questionnaire. A higher score indicates a more threatening and negative view of medical treatment. The reliability coefficient for the Indonesian version of the BMQ was $\alpha=0,915$.

\section{CAM Belief Inventory}

Patient's beliefs about traditional treatment, such as natural treatment (e.g. 'Treatments should have no negative side-effects'), participation in treatment (e.g. 'Patients should take an active role in their treatment' and holistic health (e.g. 'Health is about harmonizing your body, mind and spirit' were measure by CAM Belief Inventory through a 17-items in the questionnaire (Bishop et al., 2005). Six items assess beliefs in natural treatment, five items assess beliefs in participation in treatment and six items assess beliefs in holistic health.

Responses scores on a 7-point Likert-type scale (ranging from $1=$ strongly disagree, $4=$ uncertain, and $7=$ strongly agree). The total score was obtained by summing the scores from each item in the questionnaire. A higher score indicates a more positive view of traditional treatment. In statistical analysis, response scale of items $9,11,14$ and 17 was reserved for obtaining the same response direction with other items.

The result from CAMBI try-out process in the first psychometrics study showed that the questionnaire was internally consistent with $\alpha=0,81$ (Bishop et al., 2005). While the Cronbach's Alpha for the Indonesian version of the CAMBI was 0,446.

\section{Semi-Structured Interview}

The interview guideline was designed based on The Common Sense Model of Illness (Leventhal et al., 1980). This model explained that patient was an active individual and they gave meaning to the information about health threats and coped with the problems. The interview guideline consisted of a series of questions about breast cancer diagnosis and how the patients make a treatment decision to cope with their illness. There were few topics assessed in this interview guidelines; breast cancer diagnosis, treatment decisions, reasons to undergo a traditional treatment and how the patients view health care providers. Interview data were used to complement the quantitative data from the questionnaire.

To determine the degree of qualitative reliability and validity, we checked the interview transcript, so there is no mistake 
when the interview transcript was written before began the qualitative analysis, write a thick description of the findings, using bias and do an expert review (Creswell, 2009). Two lecturers from the Departement of Clinical Psychology were asked to do an expert review.

Procedure. This study was divided into two phase; the first one was validating all instruments through a try-out process and the second one was using the instruments to collect the data from breast cancer patients who undergo a traditional treatment. All questionnaires were translated to produce an Indonesian version using the forward and back translation method (Borsa, Dámasio \& Bandeira, 2012). The forward translation was conducted by the first author and one student from the Departement of English Literature and then, the backward translation was conducted by two students from the Faculty of Psychology. Two lecturers from the Departement of Clinical Psychology were asked to do an expert review. They assessed the significance of any discrepancies and after some revisions, the Indonesian version of the IPQ-R, BMQ and CAMBI was finalized. Before the Indonesian version of IPQ-R and BMQ were used in this study, the questionnaires were tested to 38 chronically ill patients in Bandung. The sample was recruited through an online survey and their family member was asked to help the patients completed the questionnaire. The CAMBI questionnaire was tested to 32 chronically ill patients who undergo a traditional treatment in Bandung. The sample was recruited from survey and visitation to traditional treatment clinic.

The second phase was a case study on illness perception and treatment belief in breast cancer patients who undergo a traditional treatment using the instruments that had been validated before. Breast cancer patients $(\mathrm{N}=5)$ received an explanation about the study and then if they were willing to participate in this study, the patients signed an informed consent. The participants completed the demographic and clinical characteristic form, IPQ-R, BMQ and CAMBI. After that, they were interviewed using a semi-structured interview guideline. If participant's condition worsened during the data collection phase, their caregiver and we helped them to complete the questionnaire and wrote the interview data.

The quantitative data were analyzed descriptively, which calculated mean, frequency and participant's score from all the questionnaires. Each score, both total and dimension score were categorized into a high and low category. The category was based on the group norm obtained from the try-out result of the questionnaires. The mean value was calculated from the try-out data to determine the category. The score that is below mean value was included in "low" category $(X<\mu)$ and vice versa for the "high" category $(X \geq \mu)$.

The interview data was written in word document. We read through the data and created a general sense of meaning from the data. Then the interview transcript was divided into several theme and received a label for every information. The coding was used to describe several themes that showed in the study and association between the themes. The interpretation of coding was combined to complement the quantitative data.

\section{Result}

\section{Demographic Data and Clinical Characteristic}

Data were obtained from 5 breast cancer patients as can be seen in Table 2. The participant's age range was 24-55 years old. The majority of them was a college graduate, only one participant who was a high school graduate. Most of the participants were housewives and married. Four participants had a family history of breast cancer. The majority of participants had advanced cancer (stages III 
and IV), and they had undergone surgery. All of the participants underwent a herbal treatment. And two participants combined both herbal treatment and energy therapy.

Table 1

Score Categorization Based On Try-Out Result

\begin{tabular}{lcc}
\hline \multirow{2}{*}{ Variable and Dimension } & \multicolumn{2}{c}{ Category } \\
\cline { 2 - 3 } & High & Low \\
\hline Illness Perception & & \\
Timeline (acute/chronic) & $\geq 19.08<19.08$ \\
Consequences & $\geq 18.74<18.74$ \\
Personal Control & $\geq 23.45<23.45$ \\
Treatment Control & $\geq 18.74<18.74$ \\
Illness coherence & $\geq 19.00<19.00$ \\
Timeline Cyclical & $\geq 12.42<12.42$ \\
Emotional Representation & $\geq 17.18<17.18$ \\
\hline Medical Treatment Belief & $\geq 53.13<53.13$ \\
Specific Necessity & $\geq 14.39<14.39$ \\
Specific Concern & $\geq 14.53<14.53$ \\
General Overuse & $\geq 11.71<11.71$ \\
General Harm & $\geq 12.50<12.50$ \\
\hline Traditional treatment belief & $\geq 90.41<90.41$ \\
\hline
\end{tabular}

Table 2

Demographic Data and Clinical Characteristic

\begin{tabular}{|c|c|c|c|c|c|}
\hline $\begin{array}{l}\text { Participant's } \\
\text { Identity }\end{array}$ & P1 & $\mathbf{P 2}$ & $\mathbf{P 3}$ & P4 & P5 \\
\hline Age & 32 years & 24 years & 45 years & 55 years & 52 years \\
\hline $\begin{array}{l}\text { Marital } \\
\text { status }\end{array}$ & Married & Not married & Married & Married & Married \\
\hline Education & College & College & $\begin{array}{l}\text { Senior high } \\
\text { school }\end{array}$ & College & College \\
\hline Employment & Midwife & Intern Doctor & Housewife & Housewife & Housewife \\
\hline $\begin{array}{l}\text { Family } \\
\text { history of } \\
\text { breast cancer }\end{array}$ & Yes & Yes & Yes & No & Yes \\
\hline $\begin{array}{l}\text { Stage of } \\
\text { cancer }\end{array}$ & 1 & 4 & 3 & 3 & 1 \\
\hline $\begin{array}{l}\text { Medical } \\
\text { Cancer } \\
\text { Treatment }\end{array}$ & $\begin{array}{l}\text { Hormone } \\
\text { therapy }\end{array}$ & $\begin{array}{l}\text { Surgery, } \\
\text { Chemotherapy, } \\
\text { Radiotherapy, } \\
\text { Hormone } \\
\text { therapy }\end{array}$ & $\begin{array}{l}\text { Surgery, } \\
\text { Chemotherapy, } \\
\text { Hormone } \\
\text { therapy }\end{array}$ & Surgery & Hormone therapy \\
\hline $\begin{array}{l}\text { Traditional } \\
\text { Treatment }\end{array}$ & $\begin{array}{l}\text { Herbal } \\
\text { treatment }\end{array}$ & $\begin{array}{l}\text { Herbal } \\
\text { treatment, } \\
\text { energy therapy }\end{array}$ & Herbal treatment & $\begin{array}{l}\text { Herbal } \\
\text { treatment }\end{array}$ & $\begin{array}{l}\text { Herbal treatment, } \\
\text { energy therapy }\end{array}$ \\
\hline
\end{tabular}




\section{Description of Participant's Illness Perception and Treatment Belief}

The majority of participants had a positive illness perception. All of them believed that they could control the breast cancer with their effort but also perceived their illness gave a serious consequence.

Most of the participants appraised their illness as an acute condition and believed the treatment could help them control the illness. Even so, they felt an emotional impact caused by their illness, lack of complete understanding of their condition and believed the symptoms of the illness could not be predicted.

The most selected cause of breast cancer was related to psychological factor, such as stress, problems in the family and emotional condition. The causes which considered important were associated with participant's behavior. In the first place was high fat diet, the second was genetics, the third was stress and the rest of the causes varied from lifestyle to hormonal condition.

In this study, most of the participants had a lower belief in medical treatment. All of them worried about the negative side effects of cancer treatment. They tend to feel that there was no need to undergo a medical treatment. The majority of the participants perceived a medication, in general, was not a harmful substance and could be used to maintain health. The participants also had a negative belief about how the doctors might have overprescribed the medicines.

Furthermore, the majority of participants had a higher belief in traditional treatment. The participants had a belief about natural treatment, participation in

treatment and holistic health. They believed that natural treatment was safer and effective to cure their illness rather than medical treatment. Participating in treatment process was perceived as an important aspect for them.
They also believed in holistic health because health condition was involving various aspects of the self; body, mind and soul.

Based on the result of this current study in the table 3, three participants (P1, P3 and P5) had positive illness perception, lower belief in medical treatment and higher belief in traditional treatment. One participant (P2) had a negative illness perception, a higher belief in medical treatment and a lower belief in traditional treatment. The last participant (P4) had a negative illness perception, a lower belief in medical treatment and a higher belief in traditional treatment.

\section{History of Diagnosis and Treatment Undertaken by Participants}

Other factors that contributed to the treatment decision-making process were the patient's belief in health care provider and the source of information about traditional treatment. All of the participants were diagnosed with breast cancer by a doctor and undergone the cancer medical treatment before visiting the traditional treatment clinic. Most of them used both types of treatments simultaneously and decided to use only traditional treatment. They put more trust in traditional treatment therapist to cure their condition. Reasons to utilize traditional treatment were fear of breast removal surgery, faster healing process, treatment expenses, see others bad experiences with the medical treatment and believed that traditional treatment is the best treatment which God has given.

The source of information used by the participants was varied ranging from the journal, internet to the family recommendation. Their family members and spouses also suggested them to undergo a traditional treatment for various reasons. The reasons have they supported the participants not to undergo a breast removal surgery, the traditional treatment was considered helpful in curing another member of the family and also because the treatment had better side effects. 


\section{Discussion and Conclusion}

\section{Discussion}

Our results show that the majority of breast cancer patients who underwent a traditional treatment had a positive illness perception. The participants perceived breast cancer gave serious consequences in their life, as it is a chronic illness. Chronic illness could give a pressure both to the individual who experienced it and also their families (Dobbie \& Mellor, 2008). Women with breast cancer experienced a negative stress and affective disorder such as anxiety, confusion and depression (Longman et al., 1999).

Each person would show a certain illness perception for every illness based on the symptoms and its chronicity (Leventhal et al., 1980). The participants of this study had a different level of understanding regarding their illness. Some participants perceived breast cancer as an acute condition and would heal soon, but other participants believed their illness is a chronic condition. They also believed in the fluctuations of breast cancer symptoms, whether the symptoms were predictable or unstable.

All participants believed in their ability to control their breast cancer, and most of them perceived that treatment could help them control the illness. One attempt to control the illness was undergone a traditional treatment as a mean to cope with breast cancer. Chronically ill patients could be motivated to undergo treatment to control their illness and its symptoms (Leventhal et al., 2004). This finding corresponds with two study in cancer patients in Korea (Ji-Yeon Shin et al., 2012) and breast cancer patients in Indonesia (Azhar, Achmad, Lukman, Hilmanto \& Aryandono, 2016), which indicates that the use of traditional treatment was an attempt to explore various treatment options available for them to cope with their illness.

A study on breast cancer patients who undergone traditional treatment showed that they perceived their decision as an attempt to take control during their sickness because breast cancer was associated with uncertainty (Truant \& Bottorff, 1999). Patients were able to feel more actively involved and empowered through traditional treatment and during treatment process (Barrett et al., 2003). These contribute to participant's decision to undergo a traditional treatment as one of the effort to control their illness.

As for the cause of breast cancer, participants reported that it is related to psychological factors, such as stress, family problems and emotional condition. This finding was analogous with two studies conducted in Australia (Thomson et al., 2014) and Brazil (Peuker, Armiliato, de Souza \& de Castro, 2016), where breast cancer patients believed psychological factors in the form of stress and emotional condition caused their illness. On the other hand, the causes which considered important by the participants were associated with behavioral aspects such as diet, lack of sleep, hydration, lifestyle, smoking, alcohol consumption, etc. The cause of illness which associated with participant's behavior was more controllable than other causes of illness (Shiloh et al., 2002). Patients were able to control the illness if they believed that the cause of their illness emerged from their behavior (Moss-Morris et al., 2002).

Most of the participants had lower belief in medical treatment. All of them were worried about the long-term negative side effects of medical cancer treatment. The belief that medical treatment can cause a dependency became an important contributor that medical treatment is considered harmful (Horne, 1997, Horne \& Weinman, 1999). The concern about medical treatment could make the patients not adhere and stop continuing the treatment because they had a concern about the negative consequences and adverse potential side effects from the treatment (Horne at al., 2013). There were also a few participants who believed in the necessity to undergo medical treatment. The concern about medical 
treatment could encourage the use of traditional treatment. Some participants of this study said that they feared of surgery and perceived chemotherapy as a hassle. Nevertheless, most of them viewed medical treatment in general as not harmful and safe to use.

The majority of participants had a higher belief in traditional treatment. They also put more trust in traditional treatment therapist to cure their illness. The participants believed the importance of participating in the treatment process and this factor could be associated with their belief to control their illness. The patients from a different group of illness used traditional treatment as a strategy to actively cope with the illness, included participation in treatment, gaining control and empowerment (Bishop et al., 2007). Most of the participants also perceived that natural treatment was safer to use and effective to cure their illness and believed in holistic health. Other finding showed that there was a relationship between a belief in holistic health and the use of traditional treatment (Testerman, Morton, Mason \& Ronan, 2004).

The participants used various sources to get information regarding the traditional treatment. Two participants (P1 \& P4) used the internet as a source of information about their illness and various treatment options available for them. The use of internet in cancer patients became a source of information regarding their illness and treatment options (Walsh et al., 2010). In this study, the information from the internet might influence their decision to undergo a traditional treatment. Participants also received suggestions from their family members and spouses to undergo a traditional treatment. This finding was similar with several studies in a group of cancer patients (Evans et al., 2007 \& Al-Naggar et al., 2008) and breast cancer patients (Tautz, Momm, Hasenburg \& Guethlin, 2012; Muhamad et al., 2012) where family become an important source of information about traditional treatment. Furthermore, the spouses also recommended a traditional treatment to the participants. Recommending to undergo a traditional treatment to the breast cancer patients was one form of spousal involvement in treatment decision-making process (Öhlén et al., 2006).

There were several limitations in this current study. First, this study cannot be generalized to the larger population of breast cancer patients who undergo a traditional treatment. Secondly, all questionnaires were translated from English version to Indonesian version which could create a bias in the interpretation of the instructions and the items. Based on Guilford reliability Criteria (Sugiyono, 2007), we found a suboptimal Cronbach Alpha's value in several IPQ-R dimensions and in the CAM Belief Inventory. The suboptimal Cronbach Alpha's value in Indonesian version of the IPQ-R and CAMBI could appear because we only used a small sample in try-out process, the participants were unable to understand the items and the culture differences.Schmitt (1996) argues that there is no sacred level of acceptable level of alpha and in certain case, measurements with a low level of alpha might still be useful for the interpretation. Nevertheless, we suggested that the interpretation of IPQ-R and CAMBI should be made with caution. Lastly, the future study needs to consider the duration of data collection process because the physical condition of the participants is not in optimal condition.

\section{Conclusions}

In conclusion, most breast cancer patients who undergo traditional treatment had a positive illness perception, lower belief in medical treatment and higher belief in traditional medication. Other factors that contributed to treatment decision making were the patient's belief in health care provider and the source of information about traditional treatment. 
Table 3

Summary of Quantitative Data on Illness Perception, Medical Treatment Belief and Traditional Treatment Belief

\begin{tabular}{|c|c|c|c|c|c|c|c|c|c|c|}
\hline \multirow{2}{*}{$\begin{array}{l}\text { Participant } \\
\text { Illness Perception }^{1}\end{array}$} & \multicolumn{2}{|r|}{$\mathrm{P} 1$} & \multicolumn{2}{|c|}{$\mathrm{P} 2$} & \multicolumn{2}{|r|}{ P3 } & \multicolumn{2}{|c|}{$\mathrm{P} 4$} & \multicolumn{2}{|c|}{ P5 } \\
\hline & Score & Category & Score & Category & Score & Category & Score & Category & Score & Category \\
\hline Timeline & 6 & Low & 18 & Low & 12 & Low & 21 & High & 13 & Low \\
\hline Consequences & 22 & High & 29 & High & 19 & High & 22 & High & 20 & High \\
\hline Personal Control & 30 & High & 28 & High & 24 & High & 24 & High & 24 & High \\
\hline Treatment Control & 25 & High & 21 & High & 20 & High & 15 & Low & 25 & High \\
\hline Timeline Cyclical & 12 & Low & 15 & High & 10 & Low & 15 & High & 24 & High \\
\hline Illness Coherence & 21 & High & 15 & Low & 18 & Low & 11 & Low & 19 & High \\
\hline \multirow[t]{2}{*}{ Emotional Representation } & 26 & High & 30 & High & 21 & High & 24 & High & 11 & Low \\
\hline & $\begin{array}{l}\text { Total } \\
\text { Score }\end{array}$ & Category & $\begin{array}{l}\text { Total } \\
\text { Score }\end{array}$ & Category & $\begin{array}{l}\text { Total } \\
\text { Score }\end{array}$ & Category & $\begin{array}{l}\text { Total } \\
\text { Score }\end{array}$ & Category & $\begin{array}{l}\text { Total } \\
\text { Score }\end{array}$ & Category \\
\hline \multirow[t]{2}{*}{ Medical Treatment Belief ${ }^{2}$} & 62 & $\begin{array}{l}\text { High } \\
\text { (Negative } \\
\text { View) }\end{array}$ & 53 & $\begin{array}{l}\text { Low } \\
\text { (Positive } \\
\text { view) }\end{array}$ & 59 & $\begin{array}{l}\text { High } \\
\text { (Negative } \\
\text { View) }\end{array}$ & 59 & $\begin{array}{l}\text { High } \\
\text { (Negative } \\
\text { View) }\end{array}$ & 66 & $\begin{array}{l}\text { High } \\
\text { (Negative } \\
\text { View) }\end{array}$ \\
\hline & Score & Category & Score & Category & Score & Category & Score & Category & Score & Category \\
\hline Specific Necessity & 9 & Low & 24 & High & 15 & High & 10 & Low & 11 & Low \\
\hline Specific Concern & 21 & High & 19 & High & 20 & High & 22 & High & 20 & High \\
\hline General Overuse & 20 & High & 6 & Low & 13 & High & 16 & High & 13 & High \\
\hline \multirow[t]{2}{*}{ General Harm } & 12 & Low & 4 & Low & 11 & Low & 11 & Low & 17 & High \\
\hline & $\begin{array}{l}\text { Total } \\
\text { Score }\end{array}$ & Category & $\begin{array}{l}\text { Total } \\
\text { Score }\end{array}$ & Category & $\begin{array}{l}\text { Total } \\
\text { Score }\end{array}$ & Category & $\begin{array}{l}\text { Total } \\
\text { Score }\end{array}$ & Category & $\begin{array}{l}\text { Total } \\
\text { Score }\end{array}$ & Category \\
\hline Traditional Treatment Belief $^{3}$ & 113 & High & 87 & Low & 102 & High & 92 & High & 96 & High \\
\hline
\end{tabular}

Obtained from the result of ${ }^{1}$ IPQ-R score, ${ }^{2}$ BMQ score, ${ }^{3}$ CAMBI score 


\section{References}

Al-Naggar, R. A., Bobryshev, Y. V., Abdulghani, M., Rammohan, S., Osman, M. T., \&

Kadir, S. Y. A. (2013).

Complementary/alternative medicine use among cancer patients in Malaysia. World Journal Medical Science, 8(2), 157-164. doi : 10.5829/idosi.wjms.2013.8.2.7358

Azhar, Y., Achmad, D., Lukman, K., Hilmanto, D., \& Aryandono, T. (2016). Predictors of complementary and alternative medicine use by breast cancer patients in Bandung, Indonesia. Asian Pacific Journal of Cancer Prevention, 17(4), 2115-2118. doi:http://dx.doi.org/10.7314/APJCP.2016.17. 4.2115

Barrett, B., Marchand, L., Scheder, J., Plane, M. B., Maberry, R., Appelbaum, D., ... \& Rabago, D. (2003). Themes of holism, empowerment, access, and legitimacy define complementary, alternative, and integrative medicine in relation to conventional biomedicine. The Journal of Alternative \& Complementary Medicine, 9(6), 937-947.doi: $10.1089 / 107555303771952271$

Bishop, F. L., Yardley, L., \& Lewith, G. (2005). Developing a measure of treatment beliefs: the complementary and alternative medicine beliefs inventory. Complementary therapies in medicine, 13(2), 144-149. doi: 10.1016/j.ctim.2005.01.005

Bishop, F. L., Yardley, L., \& Lewith, G. T. (2007). A systematic review of beliefs involved in the use of complementary and alternative medicine. Journal of health psychology, 12(6), 851-867. doi: $10.1177 / 1359105307082447$

Creswell, J. W. (2009). Research design: Qualitative, quantitative, and mixed methods approaches. Sage publications.

Damery, S., Gratus, C., Grieve, R., Warmington, S., Jones, J., Routledge, P., ... \& Wilson, S. (2011). The use of herbal medicines by people with cancer: a cross-sectional survey. British journal of cancer, 104(6), 927-933. doi:10.1038/bjc.2011.47

Dobbie, M., \& Mellor, D. (2008). Chronic illness and its impact: considerations for psychologists. Psychology, health \& medicine, 13(5), 583-590.doi: $10.1080 / 13548500801983041$

Evans, M., Shaw, A., Thompson, E. A., Falk, S., Turton, P., Thompson, T., \& Sharp, D. (2007). Decisions to use complementary and alternative medicine (CAM) by male cancer patients: information-seeking roles and types of evidence used. BMC Complementary and Alternative Medicine, 7(1), 25. doi:10.1186/1472-6882-7-25

Foster, G. M. \& Anderson, B.G.(2006). Health Anthropology.(P.P.Suryadarma and M.F Swasono, Eds). Jakarta: UI Press.

Home, R. (1997). Representations of medication and treatment: advances in theory and measurement (pg. 155-187). K. J. Petrie, \& J. Weinman (Eds.). London: Harwood Academic.

Horne, R., Chapman, S. C., Parham, R., Freemantle, N., Forbes, A., \& Cooper, V. (2013). Understanding patients' adherencerelated beliefs about medicines prescribed for long-term conditions: a meta-analytic review of the Necessity-Concerns Framework. PloS one, 8(12), e80633. doi : 10.1371/journal.pone.0080633

Horne, R., Weinman, J., \& Hankins, M. (1999). The beliefs about medicines questionnaire: the development and evaluation of a new method for assessing the cognitive representation of medication. Psychology and health, 14(1), 124. doi: 10.1080/08870449908407311

Indonesian Data and Information Center of Ministry of Health. 2015. Stop Cancer. Infodatin. Jakarta: Indonesian Ministry of Health. Downloaded from http://www.depkes.go.id/resources/download/ pusdatin/infodatin/infodatin-

Indonesian Ministry of Health. (2013). Basic Health Research 2013. Downloaded from www.litbang.depkes.go.id

Iskandarsyah, A., Klerk, C., Suardi, D., Soemitro, M., Sadarjoen, S., \& Passchier, J. (2013). Psychosocial and cultural reasons for delay in seeking help and non-adherence to treatment in Indonesian women with breast cancer: A qualitative study. In A. Iskandarsyah, NonAdherence in Indonesian Women with Breast Cancer and Its Determinants (pp. 23-41). Bandung: OASE Publishing House.

Leventhal, H., Brissette, I., \& Leventhal, E. (2003). The common sense model of self-regulation of health and illness. In L. Cameron \& H. Leventhal (Eds.), The self-regulation of health and illness behavior (42-94). New York, NY: Routledge. Downloaded from https://www.researchgate.net/publication/284 686251_The_Common-

Sense_Model_of_Self-

Regulation_of_Health_and_Illness_The_SelfRegulation_of_Health_and_Illness_Behaviour 
Leventhal, H., Meyer, D., \& Nerenz, D. (1980).

The common sense representation of illness danger. Dalam S. Rachman (Ed.), Contributions to medical psychology (Vol. II, page 17-30). New York, NY: Pergamon Press downloaded from http://www.academia.edu/259452/The_Comm on_Sense_Representation_of_Illness_Dangera ge

Leventhal, Halm, Horowitz, Leventhal dan Ozakinci. (2004). Living With Chronic Illness: A Contextualized Self-Regulation Approach. Dalam Sutton, S., Baum, A., \& Johnston, M. (Eds.). The Sage handbook of health psychology. (page197-240). Sage.

Moss-Morris, R., Weinman, J., Petrie, K., Horne, R., Cameron, L., \& Buick, D. (2002). The revised illness perception questionnaire (IPQR). Psychology and health, 17(1), 1-16. doi: 10.1016/S1836-9553(10)70062-X

Muhamad, M., Merriam, S., \& Suhami, N. (2012). Why breast cancer patients seek traditional healers. International journal of breast cancer, 2012. doi:10.1155/2012/689168

Nurleli, Petpichetchian, W., \& Maneewat, K. (2014). Patient delay in consulting a medical doctor among Aceh women with breast cancer. Songklanagarind Journal of Nursing, 1-11. Downloaded from www.nur.psu.ac.th/journal/file/133file\%2028 42.pdf

Öhlén, J., Balneaves, L. G., Bottorff, J. L., \& Brazier, A. S. (2006). The influence of significant others in complementary and alternative medicine decisions by cancer patients. Social science \& medicine, 63(6), 1625-1636. doi:10.1016/j.socscimed.2006.03.050

Pal, S. K. (2002). Use of alternative cancer medicine in India. Lancet Oncology, 394-395. Download from https://www.researchgate.net/publication/112 40240_Use_of_alternative_cancer_medicine_i n_India

Peuker, A. C. W., Armiliato, M. J., Souza, L. V. D., \& Castro, E. K. D. (2016). Causal attribution among women with breast cancer. Psicologia: Reflexão e Crítica, 29.doi :10.1186/s41155016-0007-y

Sarwono, Solita. (2012). Sociology of Health: Some Concepts and Its Application Fifth Edition. Yogyakarta: Gadjah Mada University Press
Schmitt, N. (1996). Uses and abuses of coefficient alpha. Psychological assessment, 8(4), 350353. doi: 10.1037/1040-3590.8.4.350

Shiloh, S., Rashuk-Rosenthal, D., \& Benyamini, Y. (2002). Illness causal attributions: an exploratory study of their structure and associations with other illness cognitions and perceptions of control. Journal of behavioral medicine, 25(4), 373-394. doi: 10.1023/A: 1015818532390

Shin, J. Y., Kim, S. Y., Park, B., Park, J. H., Choi, J. Y., Seo, H. G., \& Park, J. H. (2012). Predictors of complementary and alternative medicine use in cancer care: results of a nationwide multicenter survey in Korea. Evidence-Based Complementary and Alternative Medicine, 2012. doi:10.1155/2012/212386

Sugiyono (2007). Statistic For Research. Bandung: Alfabeta, cv.

Tautz, E., Momm, F., Hasenburg, A., \& Guethlin, C. (2012). Use of complementary and alternative medicine in breast cancer patients and their experiences: a cross-sectional study. European Journal of Cancer, 48(17), 3133-3139. doi : 10.1016/j.ejca.2012.04.021

Testerman, J. K., Morton, K. R., Mason, R. A., \& Ronan, A. M. (2004). Patient motivations for using complementary and alternative medicine. Complementary Health Practice Review, 9(2), 81-92. doi: $10.1177 / 1076167503261254$

Thomson, A. K., Heyworth, J. S., Girschik, J., Slevin, T., Saunders, C., \& Fritschi, L. (2014). Beliefs and perceptions about the causes of breast cancer: a case-control study. $B M C$ research notes, 7(1), 558 . doi: 10.1186/1756-0500-7-558

Tjindarbumi, D., \& Mangunkusumo, R. (2002). Cancer in Indonesia, present and future. Japanese journal of clinical oncology, 32 (suppl 1), page 17-21. doi : 10.1093/jjco/hye123

Tjindarbumi, D. (2005). Early Detection of Cancer and its Prevention. Jakarta: Faculty of Medicine Indonesian University Press

Truant, T., \& Bottorff, J. L. (1999). Decision making related to complementary therapies: a process of regaining control. Patient education and counseling, 38(2), 131-142. doi: 10.1016/S0738-3991(99)00060-9

Verhoef, M. J., Rose, M. S., White, M., \& Balneaves, L. G. (2008). Declining conventional cancer treatment and using complementary and alternative medicine: a problem or a challenge?. Current 
Oncology, 15(Suppl 2), 101-106. Downloaded from

https://www.ncbi.nlm.nih.gov/pmc/articles/P MC2528553/

Walsh, M. C., Trentham-Dietz, A., Schroepfer, T. A., Reding, D. J., Campbell, B., Foote, M. L., ... \& Cleary, J. F. (2010). Cancer information sources used by patients to inform and influence treatment decisions. Journal of health communication, 15(4), 445-463. doi: 10.1080/10810731003753109

World Health Organization. (2002). WHO traditional medicine strategy 2002-2005. Downloaded from www.wpro.who.int/health_technology/book_ who_traditional_medicine_strategy_2002_200 5.pdf.

Yusuf, A., Ab Hadi, I. S., Mahamood, Z., Ahmad, Z., \& Keng, S. L. (2013). Understanding the breast cancer experience: a qualitative study of Malaysian women. Asian Pacific Journal of Cancer Prevention, 14(6), 3689-3698. doi: 10.7314/APJCP.2013.14.6.36 